\title{
ARTICLE
}

Physiology

\section{The effect of brisk walking in the fasted versus fed state on metabolic responses, gastrointestinal function, and appetite in healthy men}

\author{
Victoria J. Mclver ${ }^{1} \cdot$ Lewis Mattin $^{1} \cdot$ Gethin H. Evans $^{1} \cdot$ Adora M. W. Yau $^{1}$ \\ Received: 3 May 2018 / Revised: 23 July 2018 / Accepted: 29 August 2018 / Published online: 24 September 2018 \\ (c) The Author(s) 2018. This article is published with open access
}

\begin{abstract}
Objective To investigate the effect of brisk walking in the fasted versus fed state on gastric emptying rate (GER), metabolic responses and appetite hormone responses.

Subjects/methods Twelve healthy men completed two 45 min treadmill walks, fasted (FASTED) and followed consumption of a standardised breakfast (FED). GER of a standardised lunch was subsequently measured for $2 \mathrm{~h}$ using the ${ }^{13} \mathrm{C}$-breath test method. Blood samples were collected at baseline, post-breakfast period, pre-exercise, immediately post exercise, pre-lunch then every $30 \mathrm{~min}$ following lunch for $2 \mathrm{~h}$. Circulating concentrations of acylated ghrelin (GHR), glucagon-like peptide-1 (GLP-1), peptide tyrosine tyrosine (PYY), pancreatic polypeptide (PP), glucose, insulin, triglycerides, non-esterified fatty acids (NEFA) and cholesterol were measured. Subjective feelings of appetite were assessed at 15 min intervals throughout. Substrate utilisation was measured every $30 \mathrm{~min}$, and continuously throughout exercise by indirect calorimetry.

Results No differences were observed for GER $\mathrm{T}_{1 / 2}$ (FASTED $89 \pm 22$ vs. FED $89 \pm 24 \mathrm{~min}, P=0.868$ ) nor $\mathrm{T}_{\mathrm{lag}}$ (FASTED $55 \pm 15$ vs. FED $54 \pm 14 \mathrm{~min}, P=0.704)$. NEFA concentrations were higher in FASTED at pre-exercise, post exercise and 30 min post exercise (pre-lunch) (all $P<0.05$ ) but no differences were observed for glucose, cholesterol or triglycerides. Carbohydrate oxidation was greater at all time-points during FED exercise (all $P<0.05$ ). Minimal changes in appetite were observed post lunch ingestion with no differences in PYY or GHR observed between trials. GLP-1 concentrations were greater in FED post-breakfast and pre-exercise $(P<0.05)$, though no differences were observed after lunch. A greater concentration of PP was observed in FED from pre-exercise to $30 \mathrm{~min}$ post lunch consumption (all $P<0.05$ ). Insulin concentrations were higher in FED pre-exercise but higher in FASTED $1.5 \mathrm{~h}$ post lunch $(P<0.05)$.

Conclusion These findings suggest that gastrointestinal function, hunger and appetite regulatory hormones are not sensitive to low-intensity bouts of physical activity and holds positive implications for weight management practices.
\end{abstract}

\section{Introduction}

With the prevalence of obesity reaching epidemic proportions worldwide, it remains a significant economic burden to healthcare systems globally. Intermittent fasting has been suggested as an effective method to promote health and prevent the onset of metabolic diseases by increasing insulin sensitivity and fatty-acid mobilisation, and reducing inflammation [1]. In addition, exercise alone induces health

Adora M. W. Yau

a.yau@mmu.ac.uk

1 School of Healthcare Science, Manchester Metropolitan University, Manchester M1 5GD, UK benefits, preventing the onset of metabolic diseases by modulating a range of risk factors [2-8]. Interest in the effect of fasted exercise has grown recently in both the scientific field [9-12] and the general public. However, the efficacy of whether exercising in the fasted state compared with the postprandial state is more beneficial for reducing energy intake and inducing a negative energy balance for weight loss remains unclear.

The regulation of appetite and gastrointestinal motility appears to be intrinsically linked as the rate of gastric emptying determines the time of gastric distention, which is known to be a satiety signal $[13,14]$. Therefore, the effect of fasted exercise on gastric emptying rate (GER) may be an important mechanistic consideration for subsequent food and energy intake. GER may also play a role in metabolic health as the delivery and absorption of nutrients in the 
small intestine is largely dependent on this process. Consequently, the influence of fasted exercise on gastrointestinal function is also of interest in postprandial metabolic responses. A previous study has shown postprandial glucose response to be less following fasted exercise [15]. This could be due in part to differences in GER. To the authors knowledge, no studies have investigated the effects of fasted exercise compared with fed exercise on gastrointestinal function and the consequence this may have on metabolic responses.

GER is influenced by a number of gut-derived hormones. The orexigenic hormone ghrelin (GHR) has been shown to increase GER [16, 17], whereas satiety hormones such as peptide tyrosin tyrosin (PYY), glucagon-like peptide-1 (GLP-1) and cholescystokinin have been shown to decrease GER [18-22]. Research investigating the effect of exercise interventions on appetite regulation and energy intake have tended to adopt the conventional method of participants' exercising following an overnight fast with no comparative postprandial condition [23-30]. The majority of these studies have reported that an acute bout of exercise reduces subjective ratings of hunger and alters appetiteregulating hormones, decreasing the orexigenic hormone GHR, and increasing the satiety hormones peptide YY and leptin for a period of time post exercise. It is currently unknown whether exercising in the fasted state results in different gut hormone responses to exercising in the postprandial state. Comparing the effect of an acute bout of fasted or fed exercise on appetite regulatory hormone responses may provide knowledge on the mechanisms relating to gastrointestinal function responses and appetite regulation that could potentially lead to intervention strategies or advice for individuals aiming to achieve a negative energy balance for weight loss. Studies that have measured gut hormone responses to fasted and postprandial exercise have reported fasted exercise increased GHR concentrations and fed exercise tended to elevate PYY concentration [31], whereas another observed no differences between conditions for GLP-1 (7-36) and insulin responses [15]. Furthermore, studies that have measured gut-derived appetite hormones in response to exercise have tended to measure only one or two hormones, with GHR, GLP-1 and PYY being the most common [23-30, 32]. Simultaneous measurement of these and other gut-derived appetite hormones would provide a clearer picture of the effects of exercise on appetite regulation.

Investigations on the effect of fasted versus non-fasted exercise interventions on appetite regulation and energy intake have reported fasted exercise reduces appetite [31, 32] and $24 \mathrm{~h}$ energy intake [12]. In addition, fasted exercise has been shown to increase fat oxidation [12] and provides beneficial metabolic adaptations [33]. On the other hand, some studies have found no differences between the effects of fasted or non-fasted exercise, with both inducing weight loss [34] and improving metabolic responses and body composition [10, 34]. However, these studies have typically used a high-fat $(70 \%)$ meal [31], which is not representative of a typical breakfast, compared meal-exercise sequence rather than omission of breakfast per se [35], or have not measured appetite hormone responses [33, 34]. In addition, these studies have commonly used highly trained populations and/or adopted exercise that is of higher intensity or that is reliant on the use of exercise equipment, thus, lacking exercise that can be accessible to all. These factors make it difficult to generalise the results to the wider or clinical populations and studies are required to investigate the effect of fasted exercise on appetite regulation in these populations. Brisk walking is the most popular modality of physical activity undertaken on a general population level [36], owing to it being easily accessible and with no requirement for specialised equipment. Thus, investigating whether fasted brisk walking may have more favourable benefits on appetite regulation compared with non fasted walking is of interest.

The aim of this study was to investigate the effect of brisk walking in the fasted versus fed state, on GER, and associated metabolic and appetite hormone responses. It was hypothesised (a) that GER would be different between fasted and fed exercise (b) that fasted and fed exercise would result in different appetite and metabolic responses and (c) that these differences would be mediated by respective responses in appetite hormones.

\section{Materials and methods}

\section{Participants}

Twelve recreationally active men (Mean \pm SD; age $26 \pm 5$ years; height $179 \pm 6 \mathrm{~cm}$; body mass $86 \pm 14 \mathrm{~kg}$; body mass index (BMI) $27 \pm 4 \mathrm{~kg} / \mathrm{m}^{2} ; \quad \dot{\mathrm{V}} \mathrm{O}_{2 \text { peak }} 39 \pm 6 \mathrm{ml} / \mathrm{kg} / \mathrm{min}$ ) volunteered to participate in this study. Participant number was determined by a power analysis based on data that would result in a detectable change in GER and fat oxidation with $80 \%$ power and at a significance level of $5 \%$. Participants were not taking regular medication or with any known history of respiratory, cardiovascular or chronic gastrointestinal disease as assessed by a health-screen questionnaire. All participants were also free from musculoskeletal injury and were non-smokers. All participants were informed of the details of the study both verbally and in writing prior to providing their written informed consent. The study was approved by the Faculty Ethics Committee (Reference: SE161749). 


\section{Preliminary trial}

All participants attended a preliminary trial at least 7 days prior to the first experimental trial. This visit involved the collection of anthropometric measures as well as familiarisation of breath sampling procedures. Height was measured to the nearest $0.1 \mathrm{~cm}$ using a wall-mounted stadiometer and body mass to the nearest $0.01 \mathrm{~kg}$ using electronic scales (GFK 150; Adam Equipment Co. Ltd., Milton Keynes, UK). Body fat percentage was approximated using bioelectrical impedance analysis (Omron BF306; Kyoto, Japan).

Following this, all participants completed a peak oxygen uptake $\left(\dot{\mathrm{V}}_{2 \text { peak }}\right)$ test on a motorised treadmill. Initially, the treadmill speed was adjusted until a suitable brisk walking pace was determined. Participants were advised that brisk walking is defined as an exercise intensity yielding a mild shortening of breath yet still enabling to converse. Participants maintained this speed for 5 mins. The speed of the treadmill was then increased to $8-12 \mathrm{~km} / \mathrm{h}$ and the gradient increased by $2.5 \%$ every 3 min until volitional exhaustion. Expired air was continuously collected using a breath by breath gas analyser (Metalyzer 3b, Cortex, Leipzig, Germany) and $\dot{\mathrm{O}}_{2 \text { peak }}$ was calculated by averaging the highest oxygen volume consumed over the final $1 \mathrm{~min}$ period. Heart rate was measured continuously using a heart rate monitor (Polar H7, Kempele, Finland) and participants rating of perceived exertion (RPE) [37] was recorded every $3 \mathrm{~min}$.

Before leaving the laboratory, participants were provided with food weighing scales and asked to record their physical activity and food intake in the $24 \mathrm{~h}$ before the start of their first experimental trial. Participants were then asked to replicate their activity and diet the day preceding their subsequent trial. Participants were requested to refrain from alcohol consumption, strenuous exercise and caffeine ingestion $24 \mathrm{~h}$ before trials.

\section{Experimental trials}

Participants completed two experimental trials in a randomised crossover fashion. Each trial commenced in the morning between 0800 and $0900 \mathrm{~h}$ and trials were separated by at least 7 days.

Participants were required to fast from $2000 \mathrm{~h}$ the night before experimental trials with the exception of plain water consumption and consumed $500 \mathrm{ml}$ of water $90 \mathrm{~min}$ before arrival. Upon arrival to the laboratory, participants were asked to empty their bladder before body mass was recorded. Baseline assessments of appetite (hunger, fullness, prospective food consumption and satisfaction) were made using $100 \mathrm{~mm}$ visual analogue scales (VAS) [38], and expired air samples collected for $10 \mathrm{~min}$ for the calculation of substrate utilisation. The average $\dot{\mathrm{VO}}_{2}$ and $\dot{\mathrm{VCO}}_{2}$ measurements from the last $5 \mathrm{~min}$ of expired air collection was used to calculate fat and carbohydrate oxidation rates using stoichiometric equations [39]. This sampling method for expired air was adhered to for all resting expired air samples throughout.

Following baseline measurements, participants ate the test breakfast (FED) or remained fasted (FASTED) within a $15 \mathrm{~min}$ period. The breakfast consisted of $30 \mathrm{~g}$ of breakfast cereal with $125 \mathrm{ml}$ of semi-skimmed milk. This amount was chosen based on the manufacturer's recommendation of an average serving and provided $733 \mathrm{~kJ}(175 \mathrm{kcal}), 2.75 \mathrm{~g}$ fat, $30 \mathrm{~g}$ carbohydrate and $7.2 \mathrm{~g}$ protein. Participants consumed all of the breakfast within the 15 min window. Post breakfast ratings of appetite and substrate utilisation were measured at the end of the 15 min breakfast period. Participants rested for $1 \mathrm{~h}$ before commencement of the exercise protocol. During this $1 \mathrm{~h}$ rest period, further measures of appetite were taken every $15 \mathrm{~min}$ and substrate utilisation every 30 $\min$.

The exercise protocol involved $45 \mathrm{~min}$ of brisk walking on a level motorised treadmill at the speed determined in the preliminary trial (range $5.7-6.6 \mathrm{~km} / \mathrm{h}$ ). The relative exercise intensity was $50 \pm 0.8 \% \mathrm{VO}_{2 \text { peak }}$. Heart rate and $\mathrm{RPE}$ were measured every $15 \mathrm{~min}$ throughout the exercise, with expired air measured continuously. The last $10 \mathrm{~min}$ of each 15 min segment was used to calculate substrate utilisation. Participants recovered for $30 \mathrm{~min}$ before they ingested a standardised meal. The meal was $400 \mathrm{~g}$ (one can) of chicken and sweetcorn soup (1013 kJ (242 kcal)), containing $11.8 \mathrm{~g}$ fat, $25.1 \mathrm{~g}$ carbohydrate, $8.2 \mathrm{~g}$ protein. Subjective feelings of appetite and substrate utilisation were measured every $15 \mathrm{~min}$ post exercise for a total period of $2 \mathrm{~h}$. A schematic diagram of the experimental protocol is presented in Fig. 1.

\section{Blood sampling and blood sample analysis}

An intravenous cannula was inserted into an antecubital vein, which remained in place for the duration of the trial. The cannula was kept patent with the infusion of isotonic saline after each sample collection. Blood samples were collected at baseline, post breakfast period, pre-exercise, immediately post exercise, pre-soup ingestion, then every 30 min post soup ingestion. To prevent the degradation of acylated GHR and active GLP-1, $50 \mu \mathrm{l}$ of Pefabloc (Roche Diagnostics Limited, Burgess Hill, UK) and $50 \mu \mathrm{l}$ of dipeptidyl peptidase IV inhibitor (Merck Millipore Ltd., Feltham, UK) was immediately added to blood samples. Blood samples were centrifuged at $1500 \times g$ for $15 \mathrm{~min}$ at 4 ${ }^{\circ} \mathrm{C}$ and the serum aliquoted and stored at $-80^{\circ} \mathrm{C}$ until analysis. Serum glucose, non-esterified fatty acids (NEFA), triglycerides and total cholesterol concentrations were determined in duplicate using a clinical chemistry analyser (Randox Daytona, Crumlin, UK). Circulating concentrations of acylated GHR, active GLP-1 (7-36 and 7-37 


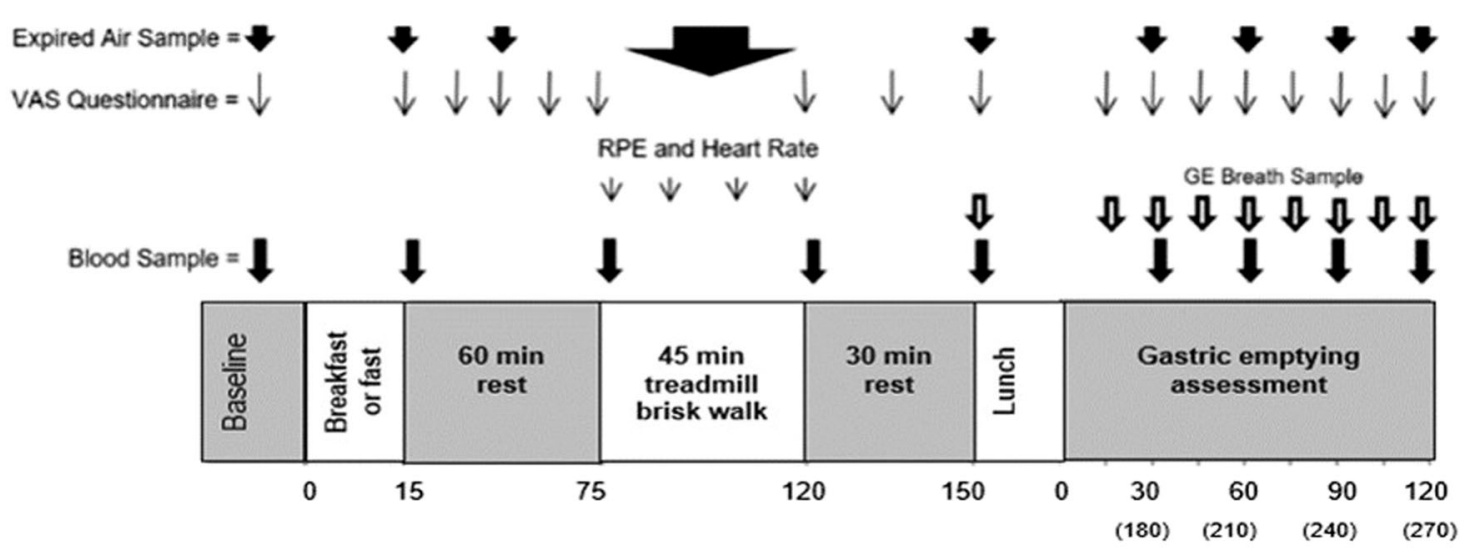

Time (min)

Fig. 1 Schematic diagram of the experimental trial protocol. RPE, rating of perceived exertion. GE, gastric emptying

forms), total PYY, pancreatic polypeptide (PP), and insulin were determined using multiplex analysis (Luminex 200, Luminex Corporation, Austin, TX, USA) with kits purchased from Merck Millipore (HMHMAG-34K, Milliplex MAP, Merck Millipore Ltd., Feltham, UK).

\section{Gastric emptying assessment}

The soup contained $100 \mathrm{mg}$ of ${ }^{13} \mathrm{C}$-sodium acetate for the assessment of GER using the ${ }^{13} \mathrm{C}$-breath test method. A basal end-expiratory breath sample was collected pre-meal ingestion then at every $15 \mathrm{~min}$ intervals post meal ingestion for $2 \mathrm{~h}$. Breath samples were analysed for the ratio of ${ }^{13} \mathrm{CO}_{2}:{ }^{12} \mathrm{CO}_{2}$ by non-dispersive infra-red spectroscopy (IRIS Dynamic, Kibion, Germany). The difference in the ratio of ${ }^{13} \mathrm{CO}_{2}:{ }^{12} \mathrm{CO}_{2}$ from baseline breath to post-ingestion breath samples are expressed as delta over baseline (DOB). Half-emptying time $\left(\mathrm{T}_{1 / 2}\right)$ and time of maximum emptying rate $\left(\mathrm{T}_{\text {lag }}\right)$ were calculated utilising the manufacturers integrated software evaluation incorporating equations of a previously described formula [40].

\section{Statistical analysis}

A two-way repeated measures analysis of variance (ANOVA) was used to assess trial $\times$ time differences in serum blood measures gastric emptying DOB, substrate oxidation and VAS ratings. Sphericity for repeated measures was assessed, and where appropriate, Greenhouse-Geisser corrections were applied for epsilon $<0.75$, and the Huynh-Feldt correction adopted for less-severe asphericity. Significant $F$ tests were followed by dependent Student's $t$ tests or one-way repeated ANOVA and Bonferroni adjusted pairwise comparisons as appropriate. Gastric emptying $T_{1 / 2}$ and $T_{\text {lag }}$ data were analysed using dependent Student's $t$ test. All analyses were carried out using IBM SPSS statistics (v22.0 for Windows; SPSS, Chicago, IL). The level of significance

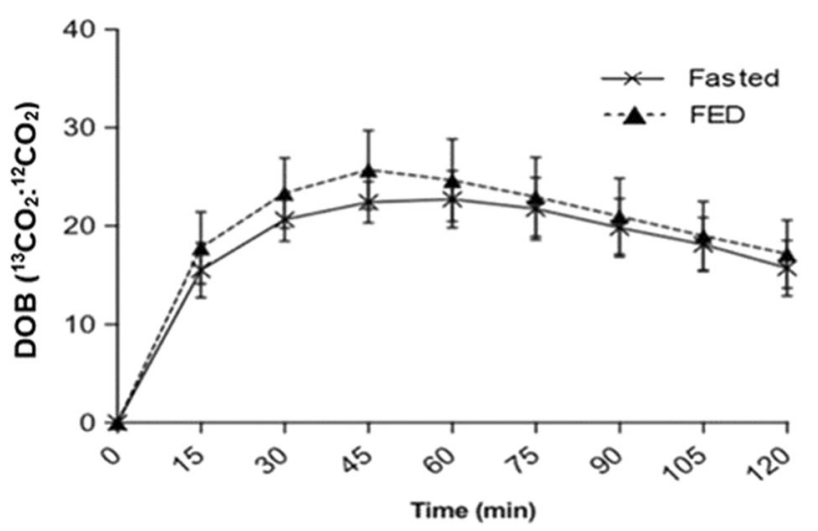

Fig. 2 Gastric emptying delta over baseline (DOB) of the lunch provided ( $400 \mathrm{~g}$ chicken and sweetcorn soup) following $45 \mathrm{~min}$ of brisk walking either fasted (FASTED) or after breakfast consumption (FED). Values were mean $\pm \mathrm{SD} ; n=12$

was set at $P<0.05$. Descriptive data are expressed as mean \pm standard deviation (SD).

\section{Results}

\section{GER}

No differences between trials (FASTED v. FED) were observed for gastric emptying $\mathrm{T}_{\mathrm{lag}}(55 \pm 15$ vs. $54 \pm 14 \mathrm{~min}$; $P=0.704)$, and $\mathrm{T}_{1 / 2}(89 \pm 22$ vs. $89 \pm 24 \mathrm{~min} ; P=0.868)$. No trial $\times$ time interaction effect $(P=0.341)$ or main effect of trial $(P=0.332)$ was detected for DOB, although, a main effect for time was found $(P<0.001)$ (Fig. 2).

\section{Subjective feelings of appetite}

A main effect of trial $(P=0.006)$, time $(P=0.006)$ and trial $\times$ time interaction effect $(P<0.001)$ was observed for 

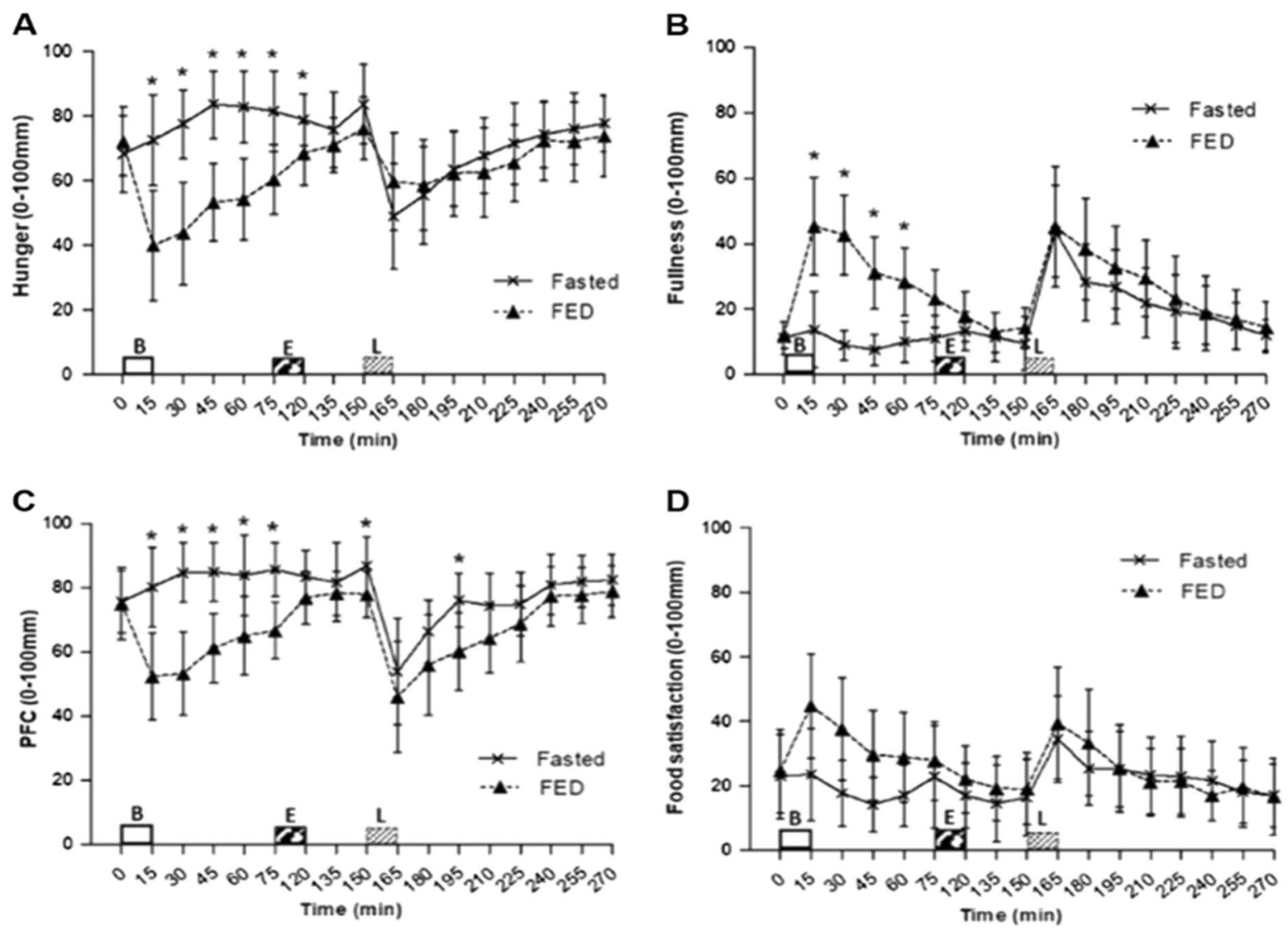

Fig. 3 Appetite scores during trials, assessed by $100 \mathrm{~mm}$ visual analogue scale (VAS); a hunger, b fullness, c prospective food consumption (PFC) and $\mathbf{d}$ food satisfaction. Values represent mean $\pm 95 \%$ CIs; $n=12$. ${ }^{*} P<0.05$ versus corresponding time point in other trial. $\mathrm{B}=$ Breakfast period, in which participants ingested a prescribed

hunger. Hunger ratings were lower post breakfast consumption in FED compared with FASTED at 15 min $(40 \pm$ 27 vs. $73 \pm 22 \mathrm{~mm}, P=0.004), 30 \mathrm{~min}(44 \pm 25$ vs. $78 \pm 17$ $\mathrm{mm}, P<0.001), 45 \mathrm{~min}(53 \pm 19$ vs. $84 \pm 17 \mathrm{~mm}, P<$ $0.001), 60 \mathrm{~min}(54 \pm 20$ vs. $83 \pm 18 \mathrm{~mm}, P<0.001)$ and 75 $\min (60 \pm 17$ vs. $81 \pm 20 \mathrm{~mm}, P=0.001)$. This remained lower immediately post exercise $(68 \pm 15$ vs. $79 \pm 13 \mathrm{~mm}$, $P=0.024$ ), however, no further differences were found following this (Fig. 3a).

A main effect of trial $(P=0.008)$, time $(P<0.001)$ and trial $\times$ time interaction effect $(P<0.001)$ was observed for fullness. Fullness was higher post breakfast consumption at $15 \mathrm{~min}(45 \pm 24$ vs. $14 \pm 18 \mathrm{~mm}, P=0.008), 30 \mathrm{~min}(43 \pm$ 19 vs. $9 \pm 7 \mathrm{~mm}, P<0.001), 45 \mathrm{~min}(31 \pm 17$ vs. $8 \pm 7 \mathrm{~mm}$, $P<0.001)$ and $60 \mathrm{~min}(28 \pm 16$ vs. $10 \pm 10 \mathrm{~mm}, P=0.007)$ in FED compared with FASTED (Fig. 3b).

A main effect of trial $(P<0.001)$, time $(P<0.001)$ and trial $\times$ time interaction effect $(P<0.001)$ was observed for prospective food consumption. A higher prospective food consumption was seen post breakfast period at $15 \mathrm{~min}$ $(80 \pm 20$ vs. $52 \pm 22 \mathrm{~mm}, P=0.004), 30 \mathrm{~min}(85 \pm 15$ vs. 53 $\pm 20 \mathrm{~mm}, \quad P<0.001), 45 \mathrm{~min} \quad(85 \pm 14$ vs. $61 \pm 17 \mathrm{~mm}$,

breakfast during the FED trial and remained fasted during the FASTED trial, $E=$ Exercise period, where participants completed a $45 \mathrm{~min}$ brisk walk, $L=$ Lunch where $400 \mathrm{~g}$ chicken and sweetcorn soup was ingested

$P<0.001), 60 \mathrm{~min}(84 \pm 20$ vs. $65 \pm 19 \mathrm{~mm}, P=0.009), 75$ $\min (86 \pm 13$ vs. $67 \pm 14 \mathrm{~mm}, P<0.001)$, post exercise prior to lunch at $150 \mathrm{~min}(87 \pm 14$ vs. $78 \pm 11 \mathrm{~mm}, P=0.014)$ and $45 \mathrm{~min}$ post lunch ingestion (76 \pm 13 vs. $60 \pm 19 \mathrm{~mm}$, $P=0.009$ ) in FASTED compared with FED (Fig. 3c).

No main effect of trial $(P=0.408)$ or trial $\times$ time interaction effect $(P=0.149)$ was observed for food satisfaction. There was a main effect of time $(P=0.011)$, however no differences between trials were found (Fig. 3d).

\section{Substrate oxidation}

No trial $\times$ time interaction effect $(P=0.096)$ or main effect of trial $(P=0.374)$ was observed for fat oxidation, although, a main effect of time was present $(P<0.001)$ (Fig. 4a). Carbohydrate oxidation also had no main effect of trial $(P=0.193)$. However, a main effect of time $(P<$ $0.001)$, and a trial $\times$ time interaction effect $(P<0.001)$ was seen. Carbohydrate oxidation was higher at $15 \mathrm{~min}(0.94 \pm$ 0.34 vs. $0.67 \pm 0.41 \mathrm{~g} / \mathrm{min} ; P=0.039), 30 \mathrm{~min}(1.16 \pm 0.28$ vs. $0.87 \pm 0.35 \mathrm{~g} / \mathrm{min} ; P=0.023)$ and $45 \mathrm{~min}(1.03 \pm 0.29$ 


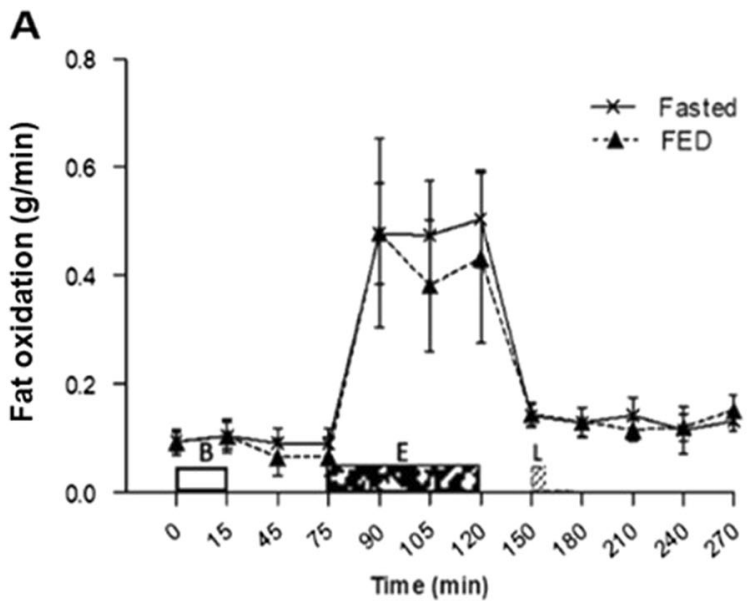

Fig. 4 Substrate utilisation throughout both trials. a Fat oxidation and b carbohydrate $(\mathrm{CHO})$ oxidation . Values represent mean $\pm 95 \%$ CIs; $n=12$. $* P<0.05$ versus corresponding time point in other trial. $B=$ Breakfast period, in which participants ingested a prescribed breakfast

vs. $0.74 \pm 0.30 \mathrm{~g} / \mathrm{min} ; P=0.015)$ of exercise in FED compared with FASTED (Fig. 4b).

\section{Metabolic markers}

No main effects of trial or trial $\times$ time interaction effects was seen for blood glucose concentration $(P=0.128$ and $P=$ 0.217; Fig. 5a) and cholesterol concentration $(P=0.930$ and $P=0.383$; Fig. 5 c $)$. No main effect of trial $(P=0.729)$ but a trial $\times$ time interaction effect tending to significance $(P=0.056)$ was seen for triglycerides concentration (Fig. 5b). Main effects of time were seen for blood glucose, triglycerides and cholesterol (all $P<0.001$ ).

A main effect of trial $(P=0.037)$, time $(P<0.001)$ and trial $\times$ time interaction effect $(P<0.001)$ was seen for NEFA concentration (Fig. 5d). NEFA concentrations in the FASTED trial were greater post breakfast period (preexercise $)$ at $75 \mathrm{~min}(0.39 \pm 0.26$ vs. $0.09 \pm 0.06 \mathrm{mmol} / \mathrm{l} ; P$ $=0.003)$, immediately post exercise at $120 \mathrm{~min}(0.90 \pm 0.48$ vs. $0.54 \pm 0.32 \mathrm{mmol} / \mathrm{l} ; P=0.004)$, and pre-lunch ingestion at $150 \mathrm{~min}(0.56 \pm 0.22$ vs. $0.42 \pm 0.19 \mathrm{mmol} / \mathrm{l} ; P=0.009)$. However, NEFA concentrations were higher in the FED trial compared with the FASTED at $1.5 \mathrm{~h}$ post soup consumption $(0.32 \pm 0.27$ vs. $0.16 \pm 0.11 \mathrm{mmol} / \mathrm{l} ; P=0.018)$.

\section{Gut Hormones}

No main effect of trial, main effect of time or trial $\times$ time interaction effect was seen for GHR concentrations $(P=$ $0.192, P=0.134, P=0.110$, respectively; Fig. 6a) or PYY concentrations $(P=0.929, P=0.382, P=0.839$, respectively; Fig. 6c).

For GLP-1, there was a main effect of trial $(P=0.017)$ but no main effect of time $(P=0.351)$ or trial $\times$ time

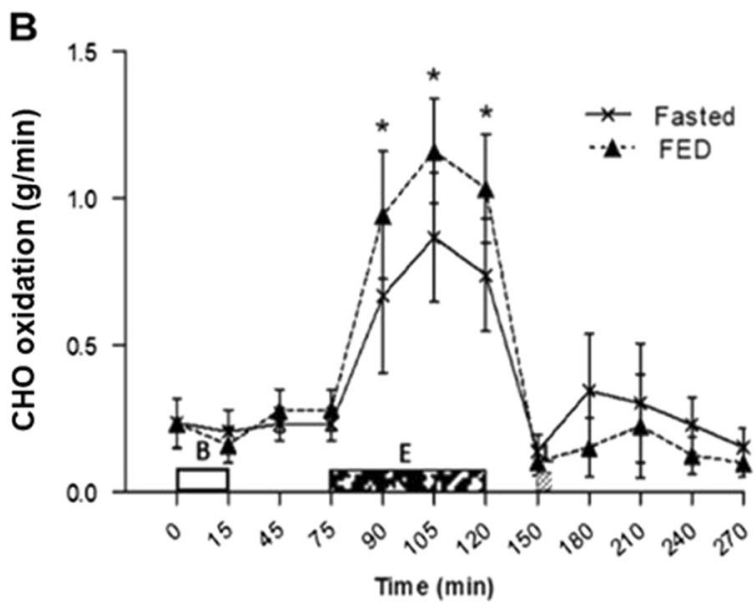

during the FED trial and remained fasted during the FASTED trial, E $=$ Exercise period, where participants completed a 45 min brisk walk, $L=$ Lunch where $400 \mathrm{~g}$ chicken and sweetcorn soup was ingested

interaction effect $(P=0.104)$. GLP-1 concentrations were higher in the FED compared with FASTED trial post breakfast at $15 \mathrm{~min}(5.86 \pm 7.26$ vs. $3.21 \pm 4.98 \mathrm{pmol} / \mathrm{l} ; P=$ $0.014), 1 \mathrm{~h}$ post breakfast at $75 \min (3.44 \pm 4.14$ vs. $2.45 \pm$ $3.74 \mathrm{pmol} / \mathrm{l} ; P=0.012)$ and pre-lunch at $150 \mathrm{~min}(4.09 \pm$ 6.46 vs. $2.68 \pm 5.14 \mathrm{pmol} / \mathrm{l} ; P=0.033$ ) (Fig. $6 \mathrm{~b}$ ).

A main effect of trial $(P=0.019)$, a main effect of time $(P=0.008)$ and a trial $\times$ time interaction effect was observed for PP $(P=0.012)$ (Fig. 6d). PP concentrations were higher during FED compared with FASTED preexercise at $75 \mathrm{~min}(23.42 \pm 17.57$ vs. $10.99 \pm 2.76 \mathrm{pmol} / \mathrm{l} ; P$ $=0.036)$, post exercise at $120 \mathrm{~min}(95.11 \pm 99.70$ vs. 29.37 $\pm 42.73 \mathrm{pmol} / \mathrm{l} ; P=0.016$ ), $30 \mathrm{~min}$ post exercise at $150 \mathrm{~min}$ $(30.96 \pm 24.41$ vs. $14.60 \pm 13.82 \mathrm{pmol} / \mathrm{l} ; P=0.017)$, and 30 min post soup consumption at $180 \mathrm{~min}(67.35 \pm 44.18$ vs. $42.96 \pm 27.11 \mathrm{pmol} / \mathrm{l} ; P=0.010)$.

No main effect of trial $(P=0.529)$ but a main effect of time $(P<0.001)$ and a trial $\times$ time interaction effect $(P<$ $0.001)$ was seen for insulin concentrations. Insulin concentrations were higher during FED compared with FASTED immediately post breakfast at $15 \mathrm{~min}(139.56 \pm 86.54$ vs. $81.59 \pm 55.91 \mathrm{pmol} / \mathrm{l} ; P=0.010)$ and pre-exercise at 75 $\min (119.11 \pm 65.28$ vs. $74.18 \pm 58.56 \mathrm{pmol} / \mathrm{l} ; P=0.001)$. Insulin concentrations increased in the FASTED trial greater than the FED trial $1.5 \mathrm{~h}$ post soup consumption at $240 \mathrm{~min} \quad(86.04 \pm 48.18$ vs. $69.09 \pm 49.29 \mathrm{pmol} / \mathrm{l} ; \quad P=$ 0.006) (Fig. 6e).

\section{Discussion}

Fasted brisk walking did not result in any difference in GER of a subsequent meal compared with brisk walking in the postprandial state. Minimal differences in perception of 

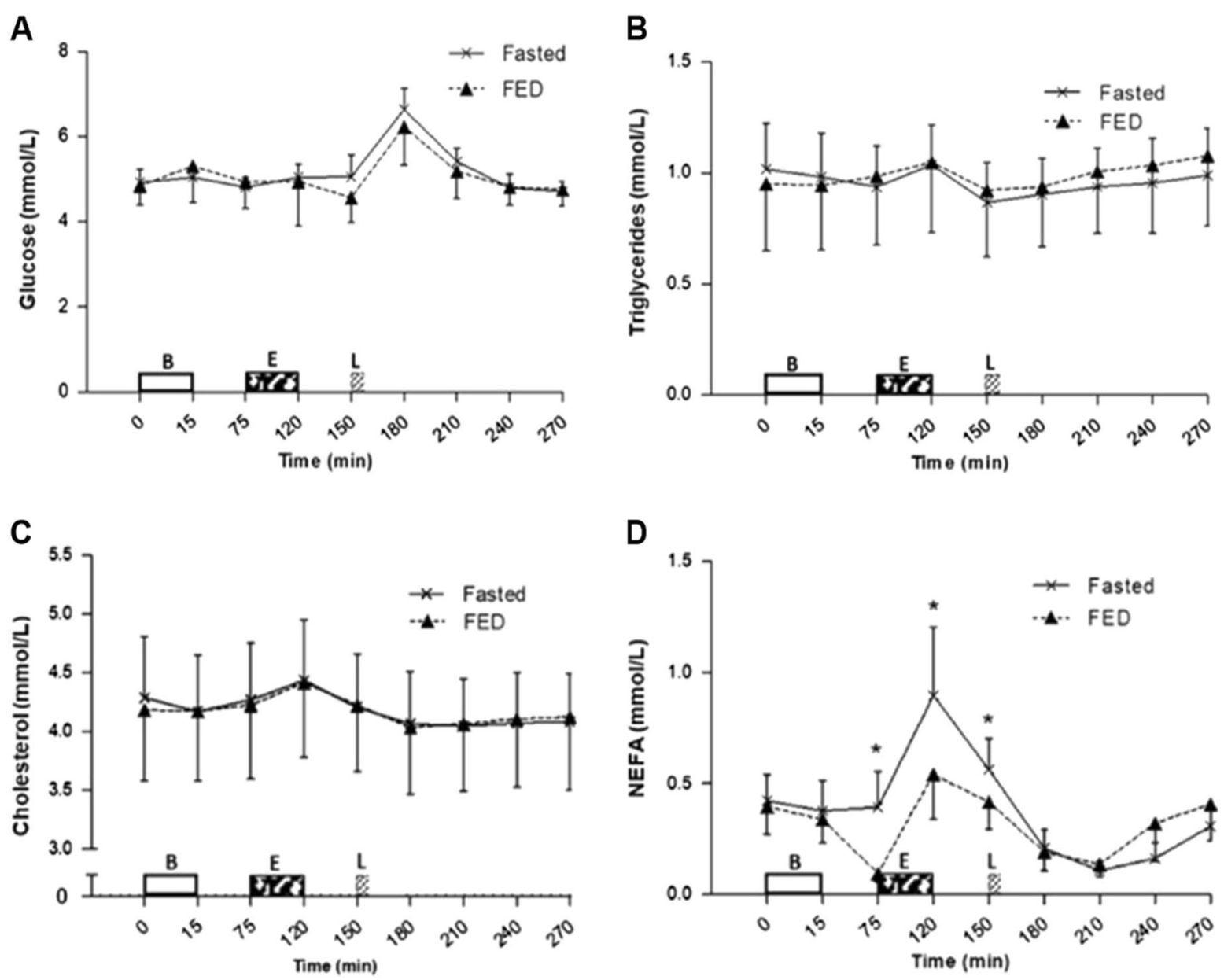

Fig. 5 Metabolic responses during trials. Serum concentrations of a glucose, $\mathbf{b}$ triglycerides, $\mathbf{c}$ cholesterol and $\mathbf{d}$ non-esterified fatty acids (NEFA). Values represent mean $\pm 95 \%$ CIs; $n=12 .{ }^{*} P<0.05$ versus corresponding time point in other trial. $\mathrm{B}=$ Breakfast period, in which

appetite post exercise were observed. Fasted exercise had limited effects on metabolic and gut hormone responses compared with exercise performed after breakfast ingestion. These findings suggest that fasted low-intensity exercise may not elicit a compensatory effect of energy intake in the immediate hours following exercise.

To the authors knowledge, this is the only study that has investigated GER between fasted vs. fed exercise. A difference in GER between trials may not have been observed in this present study owing to a relatively low meal volume and energy content. Alternatively, no difference may have been seen owing to the high variation in participants BMI and body fat percentages. Studies investigating the influence of BMI on GER are inconsistent, with some studies reporting no differences in GER according to BMI, whereas some have [41-44]. The present study used a soup meal that contained a large liquid component. The transient differences in GLP-1 and PP concentrations prior to lunch may potentially affect the emptying rate of a solid meal instead

participants ingested a prescribed breakfast during the FED trial and remained fasted during the FASTED trial, $\mathrm{E}=$ Exercise period, where participants completed a 45 min brisk walk, $L=$ Lunch where $400 \mathrm{~g}$ chicken and sweetcorn soup was ingested

owing to a greater delay of emptying with solid food compared with liquids [45]. A suppression of appetite and the orexigenic hormone acylated GHR has been consistently reported during and briefly following moderate-tohigh intensity bouts of running exercise [24, 29, 30]. However, in the present study, GHR was not suppressed post exercise in either trial. This lack of suppression is consistent with observations by King et al. [26] who also failed to observe an immediate difference in GHR following an acute bout of walking exercise. The reduced physiological challenge imposed by brisk walking compared with running exercise of a higher intensity may account for these conflicting effects of exercise.

Concentrations of the satiety hormone PYY has also been shown to increase with an acute bout of aerobic exercise [27, 29]. However, the present study showed a lack of difference in PYY concentrations over time and between trials, especially post exercise, which coincides with the subsequent hunger and satiety ratings. These results may be 

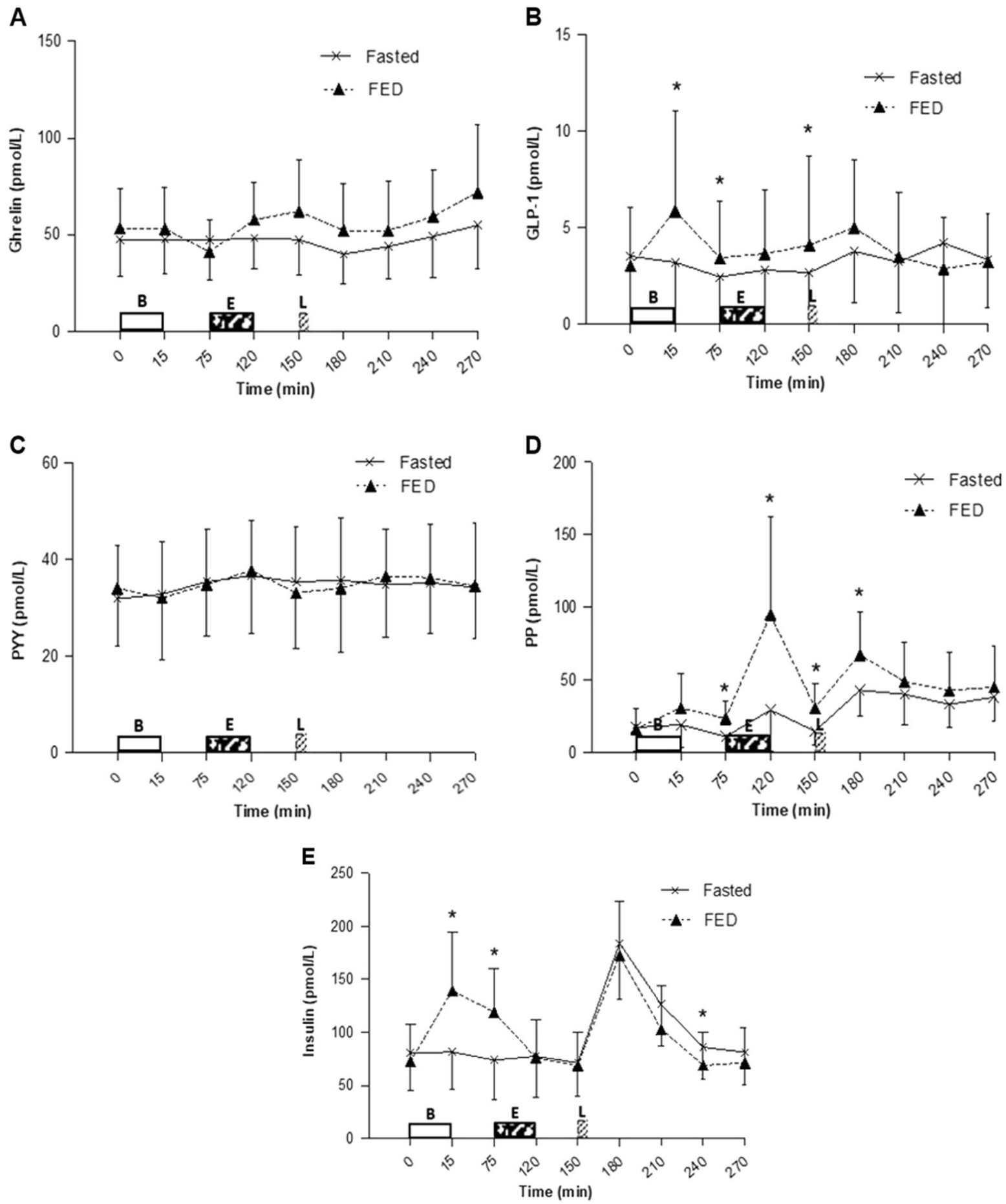

Fig. 6 Hormonal responses during both trials. Serum concentrations of a ghrelin $(n=12)$, b glucagon-like peptide-1 (GLP-1) $(n=10)$, c Peptide tyrosin tyrosin (PYY) $(n=10)$, d Pancreatic polypeptide (PP) $(n=11)$ and $\mathbf{e}$ Insulin $(n=12)$. Values represent mean $\pm 95 \%$ CIs. $* P$ $<0.05$ versus corresponding time point in other trial. $\mathrm{B}=$ Breakfast

owing to the relatively small calorie content of the breakfast provided within the present study $(724 \mathrm{~kJ}(173 \mathrm{kcal}))$ in comparison with those provided in most other investigations (typically > $1674 \mathrm{~kJ}(400 \mathrm{kcal})$ ). In addition, total PYY period, in which participants ingested a prescribed breakfast during the FED trial and remained fasted during the FASTED trial, $E=$ Exercise period, where participants completed a 45 min brisk walk, $\mathrm{L}=\mathrm{Lunch}$ where $400 \mathrm{~g}$ chicken and sweetcorn soup was ingested

was measured in the present study. The measurement of the active form $\mathrm{PYY}_{3-36}$ Would have been more desirable.

The findings for GLP-1 and PP are in agreement with previous literature regarding elevated levels following 
food consumption. PP levels remained higher in the FED trial post exercise, which is consistent with literature reporting elevated PP levels following acute exercise performed in the fed state with no effect on GHR levels [46]. Elevated concentrations of GLP-1 and PP are often accompanied by decreased perceptions of hunger [25, 47]. This is reflected within the findings of the present study until post exercise where the hunger scores dissociate from PP as hunger did not change post exercise. A possible explanation for this is that hunger ratings may be influenced more by PYY and GHR concentrations. The combined lack of differences in these hormones and hunger post exercise could suggest that regardless of an increased energy expenditure being incurred from the exercise, there will likely be no compensatory increase in energy intake post exercise to account for the omission of energy intake prior to the exercise. This may, therefore, create a small shortterm negative energy balance and if sustained in the longterm, the cumulative effects may have an important role in weight maintenance. However, it is important to consider that although appetite is anticipated to reflect energy intake, the two do not always correlate, and a delayed response in energy intake may still be possible, although some studies have not reported this finding [48, 49]. Further research on both the shorter-term effects of an acute bout of exercise and the cumulative effects of fasted exercise over a period of time is required.

Fasted brisk walking did not alter glycaemic, triglyceride or cholesterol responses to subsequent meal ingestion. However, concentrations of NEFA were greater in the FASTED trial pre- and post exercise, then lower post subsequent meal ingestion. Increased NEFA prior to the lunch meal indicates greater fat mobilisation for metabolism and is consistent with the knowledge that fat oxidation is increased with fasting, although the results of the present study only show a tendency of increased fat oxidation during fasted exercise. This may have been due to the relatively low intensity of exercise performed in this study. However, carbohydrate was the preferred substrate for exercise in this trial rather than fat stores owing to the provision of exogenous carbohydrate from the breakfast consumption.

In conclusion, these findings demonstrate that GER, appetite and appetite regulatory hormones are not sensitive to an acute bout of low-intensity exercise in the fasted state compared with the fed state. The indication that no compensatory increase in energy intake will occur post exercise potentially holds positive implications for fasted brisk walking in the long-term control of body mass. Future research is warranted to investigate the influence of fasted exercise on appetite and appetite regulatory hormones over an extended duration to help further understanding on the influence of fasted exercise on energy balance and metabolic health.
Acknowledgements We acknowledge Dave Maskew of Manchester Metropolitan University for his technical support in the laboratory.

Author contributions VJM, AMWY, GHE conceived and designed the experiments; VJM, LM, AMWY and GHE performed the experiments; VJM analysed the data; VJM wrote the paper with contributions from AMWY and GHE. All authors have read and approved the final manuscript.

\section{Compliance with ethical standards}

Conflict of interest The authors report no conflicts of interest in this work. This research received no specific grant from any funding agency in the public, commercial or not-for-profit sectors. VJM was supported by a Manchester Metropolitan University Vice Chancellor Studentship.

Open Access This article is licensed under a Creative Commons Attribution 4.0 International License, which permits use, sharing, adaptation, distribution and reproduction in any medium or format, as long as you give appropriate credit to the original author(s) and the source, provide a link to the Creative Commons license, and indicate if changes were made. The images or other third party material in this article are included in the article's Creative Commons license, unless indicated otherwise in a credit line to the material. If material is not included in the article's Creative Commons license and your intended use is not permitted by statutory regulation or exceeds the permitted use, you will need to obtain permission directly from the copyright holder. To view a copy of this license, visit http://creativecommons. org/licenses/by/4.0/.

\section{References}

1. Mattson MP, Longo VD, Harvie M. Impact of intermittent fasting on health and disease processes. Ageing Res Rev. 2016;39:46-58.

2. Rennie KL, McCarthy N, Yazdgerdi S, Marmot M, Brunner E. Association of metabolic syndrome with both vigorous and moderate physical activity. Int J Epidemiol. 2003;32:600-6.

3. Speakman JR, Selman C. Physical activity and resting metabolic rate. Proc Nutr Soc. 2003;62:621-34.

4. Borghouts LB, Keizer HA, Ivy JL. Exercise and insulin sensitivity: a review. Int J Sports Med. 2000;21:1-12.

5. Mann S, Beedie C, Jimenez A. Differential effects of aerobic exercise, resistance training and combined exercise modalities on cholesterol and the lipid profile: review, synthesis and recommendations. Sports Med. 2014;44:211-21.

6. Steig AJ, Jackman MR, Giles ED, Higgins JA, Johnson GC, Mahon $\mathrm{C}$, et al. Exercise reduces appetite and traffics excess nutrients away from energetically efficient pathways of lipid deposition during the early stages of weight regain. Am J Physiol Regul Integr Comp Physiol. 2011;301:656-67.

7. Whelton SP, Chin A, Xin X, He J. Effect of aerobic exercise on blood pressure: a meta-analysis of randomized, controlled trials. Ann Intern Med. 2002;136:493-503.

8. Thompson PD, Crouse SF, Goodpaster B, Kelley D, Moyna N, Pescatello L. The acute versus the chronic response to exercise. Med Sci Sports Exerc. 2001;33:38-45.

9. Burke LM. Fuelling strategies to optimize performance: training high or training low? Scand J Med Sci Sports. 2010;2:48-58.

10. Gillen JB, Percival ME, Ludzki A, Tarnopolsky MA, Gibala MJ. Interval training in the fed or fasted state improves body 
composition and muscle oxidative capacity in overweight women. Obesity. 2013;21:2249-55.

11. Vieira AF, Costa RR, Macedo RCO, Coconcelli L, Kruel LFM. Effects of aerobic exercise performed in fasted $\mathrm{v}$. fed state on fat and carbohydrate metabolism in adults: a systematic review and meta-analysis. Br J Nutr. 2016;116:1153-64.

12. Bachman JL, Deitrick RW, Hillman AR. Exercising in the fasted state reduced 24-hour energy intake in active male adults. J Nutr Metab. 2016;21:1984-198.

13. Horner KM, Byrne NM, Cleghorn GJ, Naslund E, King NA. The effects of weight loss strategies on gastric emptying and appetite control. Obes Rev. 2011;12:935-51.

14. Horner KM, Schubert MM, Desbrow B, Byrne NM, King NA. Acute exercise and gastric emptying: a meta-analysis and implications for appetite control. Sports Med. 2015;45:659-78.

15. Gonzalez JT, Veasey RC, Rumbold PL, Stevenson EJ. Breakfast and exercise contingently affect postprandial metabolism and energy balance in physically active males. Br J Nutr. 2013;110: 721-32.

16. Falken Y, Webb DL, Abraham-Nordling M, Kressner U, Hellstrom PM, Naslund E. Intravenous ghrelin accelerates postoperative gastric emptying and time to first bowel movement in humans. Neurogastroent Motil. 2013;25:474-80.

17. Levin F, Edholm T, Schmidt PT, Gryback P, Jacobsson H, Degerblad M, et al. Ghrelin stimulates gastric emptying and hunger in normal-weight humans. J Clin Endocrin Metab. 2006; 91:3296-302.

18. Edholm T, Degerblad M, Gryback P, Hilsted L, Holst JJ, Jacobsson H, et al. Differential incretin effects of GIP and GLP-1 on gastric emptying, appetite, and insulin-glucose homeostasis. Neurogastroenterol Motil. 2010;22:1191-201.

19. Wettergren A, Schjoldager B, Mortensen PE, Myhre J, Christiansen J, Holst JJ. Truncated glp-1 (proglucagon 78-107-amide) inhibits gastric and pancreatic functions in man. Dig Dis Sci. 1993;38:665-73.

20. Witte AB, Gryback P, Holst JJ, Hilsted L, Hellstrom PM, Jacobsson H, et al. Differential effect of PYY1-36 and PYY3-36 on gastric emptying in man. Regul Pept. 2009;158:57-62.

21. Schwizer W, Borovicka J, Kunz P, Fraser R, Kreiss C, D'Amato $\mathrm{M}$, et al. Role of cholecystokinin in the regulation of liquid gastric emptying and gastric motility in humans: Studies with the CCK antagonist loxiglumide. Gut. 1997;41:500-4.

22. Liddle RA, Morita ET, Conrad CK, Williams JA. Regulation of gastric emptying in humans by cholescystokinin. J Clin Invest. 1986;77:992-6.

23. Tiryaki-Sonmez G, Ozen S, Bugdayci G, Karli U, Ozen G, Cogalgil S, et al. Effect of exercise on appetite-regulating hormones in overweight women. Biol Sport. 2013;30:75-80.

24. Vatansever-Ozen S, Tiryaki-Sonmez G, Bugdayci G, Ozen G. The effects of exercise on food intake and hunger: relationship with acylated ghrelin and leptin. J Sports Sci Med. 2011;10:283-91.

25. Kawano H, Mineta M, Asaka M, Miyashita M, Numao S, Gando $\mathrm{Y}$, et al. Effects of different modes of exercise on appetite and appetite-regulating hormones. Appetite. 2013;66:26-33.

26. King JA, Wasse LK, Broom DR, Stencil DJ. Influence of brisk walking on appetite, energy intake, and plasma acylated ghrelin. Med Sci Sports Exerc. 2010;42:485-92.

27. King JA, Wasse LK, Ewens J, Crystallis K, Emmanuel J, Batterham RL, et al. Differential acylated ghrelin, peptide YY3-36, appetite, and food intake responses to equivalent energy deficits created by exercise and food restriction. J Clin Endocrinol Metab. 2011;96:1114-21.

28. Douglas JA, King JA, McFarlane E, Baker L, Bradley C, Crouch $\mathrm{N}$, et al. Appetite, appetite hormone and energy intake responses to two consecutive days of aerobic exercise in healthy young men. Appetite. 2015;92:57-65.
29. Broom DR, Batterham RL, King JA, Stensel DJ. Influence of resistance and aerobic exercise on hunger, circulating levels of acylated ghrelin, and peptide YY in healthy males. Am J Physiol Integr Comp Physiol. 2009;296:29-35.

30. Broom DR, Stensel DJ, Bishop NC, Burns SF, Miyashita M. Exercise-induced suppression of acylated ghrelin in humans. J Appl Physiol. 2007;102:2165-71.

31. Cheng MH, Busshnell D, Cannon DT, Kem M. Appetite regulation via exercise prior or subsequent to high-fat meal consumption. Appetite. 2009;52:193-8.

32. Deighton K, Barry R, Connon CE, Stensel DJ. Appetite, gut hormone and energy intake responses to low volume sprint interval and traditional endurance exercise. Eur J Appl Physiol. 2013;113:1147-56.

33. Van Proeyen K, Szlufcik K, Neilens H, Ramaekers M, Hespel P. Beneficial metabolic adaptations due to endurance exercise training in the fasted state. J Appl Physiol. 2011;110:236-45.

34. Schoenfeld BJ, Aragon AA, Wilborn CD, Krieger JW, Sonmez GT. Body composition changes associated with fasted versus nonfasted aerobic exercise. J Int Soc Sports Nutr. 2014;11:7-54.

35. Borer KT, Wuorinen E, Chao C, Burant C. Exercise energy expenditure is not consciously detected due to oro-gastric, not metabolic, basis of hunger sensation. Appetite. 2005;45:177-81.

36. London Sport Insight Team. 10 min brisk walking each day in mid-life for health benefits and towards achieving physical activity recommendations. Evidence Summary. Public Health England. 2017; 4-12.

37. Borg G. An introduction to Borg's RPE-scale. Ithaca, NY: Movement Publications; 1985.

38. Flint A, Raben A, Blundell JE, Astrup A. Reproducibility, power and validity of visual analogue scares in assessment of appetite sensations in single test meal studies. Int $\mathrm{J}$ Obes Relat Metab Disord. 2000;24:38-48.

39. Péronnet F, Massicotte D. Table of nonprotein respiratory quotient: An update. Can J Sport Sci. 1991;16:23-29.

40. Ghoos YF, Maes BD, Geypens BJ, Mys G, Hiele MI, Rutgeerts $\mathrm{PJ}$, et al. Measurement of gastric-emptying rate of solids by means of a carbon-labeled octanoic-acid breath test. Gastroenterology. 1993;104:1640-7.

41. Hellmig S, Von Schöning F, Gadow C, Katsoulis S, Hedderich J, Fölsch UR, et al. Gastric emptying time of fluids and solids in healthy subjects determined by $13 \mathrm{C}$ breath tests: influence of age, sex and body mass index. J Gastroenterol Hepatol. 2006;21:1832-8.

42. Buchholz V, Berkenstadt H, Goitein D, Dickman R, Bernstine H, Rubin M. Gastric emptying is not prolonged in obese patients. Surg Obes Relat Dis. 2013;9:714-7.

43. Wright RA, Krinsky S, Fleeman C, Trujillo J, Teague E. Gastric emptying and obesity. Gastroenterology. 1983;84:747-51.

44. Lavigne ME, Wiley ZD, Meyer JH, Martin P, MacGregor IL. Gastric emptying rates of solid food in relation to body size. Gastroenterology. 1978;74:1258-60.

45. Hellstrom PM, Gryback P, Jacobsson H. The physiology of gastric emptying. Best Pract Res Clin Anaesthesiol. 2006;20:397-407.

46. Martins C, Morgan LM, Bloom SR, Robertson MD. Effects of exercise on gut peptides, energy intake and appetite. J Endocrinol. 2007;193:251-8.

47. Koska J, DelParigi A, De Courten B, Weyer C, Tataranni PA. Pancreatic polypeptide is involved in the regulation of body weight in Pima Indian male subjects. Diabetes. 2004;53:3091-6.

48. Clayton DJ, Barutcu A, Machin C, Stensel DJ, James JL. Effect of breakfast omission on energy intake and evening exercise performance. Med Sci Sports Exerc. 2015;47:2645-52.

49. Levitsky DA, Pacanowski CR. Effect of skipping breakfast on subsequent energy intake. Physiol Behav. 2013;119:9-16. 